\title{
Green Computing case study: calls for proposing solutions for the Arabian Gulf Oil Company
}

\author{
Wisam H. Benamer ${ }^{1 *}$, Ebitisam K. Elberkawi ${ }^{1}$, Nebras A. Neihum ${ }^{1}$, Anwiji S. Anwiji ${ }^{1}$, and Moatz A. Youns ${ }^{1}$ \\ ${ }^{1}$ Faculty of Information Technology, Information system Department, University of Benghazi, Libya
}

\begin{abstract}
Nowadays technology-based means are elements in every-day's life, they ease running household and institution needs. In Libya the number of newly established institutions is on the rise in both the private and public sectors, with such growth there must be a concomitant increase in the use of electronic devices/gadgets. However, after a while these electronic devices will be out of date, and here a suitable strategy of Green Computing must be considered. This study aims to shed light on ways to save electricity consumption as a main factor for green computing, and to help publicize the understanding of green computing in institutions. Furthermore, awareness of green computing importance will be raised, through introducing the green computing concept to companies using a field study. The current study is a trial and was conducted in one of the biggest companies in Libya, namely the Arabian Gulf Oil Company (AGOCO). Consequently, we had come up with a number of recommendations that were classified into general and specific. General recommendations: These deal with the concept of green computing and what must be done to implement the steps for its correct application. Specific recommendations: These reflect the company's plans to enhance power saving through green computing that are suitable for running their daily business.
\end{abstract}

Keywords- Green Computing; Green IT; Environment; Sustainable Energy; Energy-Aware; Eco Friendly Computing.

*Corresponding author: wisam.benamer@uob.edu.ly 


\section{INTRODUCTION}

Green computing is defined as the use, manufacturing and designing recyclable devices to protect the environment from pollution and thus make it healthier. In addition saving power is another factor that helps push for safer and cleaner eco system [1].

Our Institutions and community are in urging need to adopt the concept of green computing. Going green makes the environment healthier, saves more energy and reduces the energy waste. Fostering this concept makes the pressure on the electricity company recedes, hence, we help relate green technology with green life.

Global warming is a major problem that faces the world, affecting institutions of private and governmental sectors, thus all communities have to create new business plans that focus on finding solutions for environmental issues [2].

Using the green computing in all sectors will produce a positive impact in the environment, running cost and global warmth [2]. Going green in addition will save natural resources, especially those under the threat of depletion. Green computing has a good empowering impact on the society and environment because it essentially means recycling, good economy, carbon dioxide and hazardous materials reduction, maximizing energy efficiency during the product's life time. It stems from the reduction in fossil fuel used in power plants and transportation [3]. Dell, CSC, Google, HP, Intel, Lenovo and Microsoft are all big companies that express their commitment to the greening concept by purchasing energy-efficient desktops and servers [4].

This study was driven by various motivations: Raise awareness for saving the environment in Libya; Boosting the economy by saving the power energy; increasing the quality of companies' management; laying the foundations necessary to reach a primary goal to take an actual first step towards green computing; Estimating the extent of awareness towards green computing concept. Institutions, companies and organizations in Libya need to adopt the concept of green computing into their daily work. They need to run introductory seminars for their employees to spread awareness for environment friendly available e-products, and how to dispose them in a way that benefits the environment or at least does not harm it. There are so many ways for higher institutions to turn green. They can start by running introductory seminars for their staff, and plan to using data centers. Companies must establish a plan to put green computing into action, at least by emphasizing putting computers to the sleep mode to save energy [5].

This study aims to raise the level of awareness for the importance of green computing, and to highlight any obstacles that prevent the adoption of such concept. In addition to saving energy, awareness should be directed towards excessive consumption of electricity and harmful emissions resulting from the use of electronic devices. To run such a study the administrative site of the local well known AGOCO Libyan Company was chosen. The study was conducted through running interviews with the specialized employee to eventually reach a new technical proposal that contributes to the compatibility of the company's work with the green environment. Finally, several helpful recommendations were reached that were categorized into general and specific categories.

\section{Related work}

Research in [6] presented a study that shows the different percentages of growth of the internet in different countries over the years. This growth is considered as a factor that impacts data centers' differences in the adoption of green computing. The current work refers to other factors currently affecting the differences in green computing adoptions, and some of them are: Increasing energy cost; Low server utilization rates; Awareness of its impact on the environment. All industries that handle business equipment have a strong impact on green computing. The society has challenges with regard to green computing establishment, such as understanding the objectives of green computing. Companies must expend for initiatives and awareness about going green. The study presented green manufactured products such as: Bamboo, recyclable plastics, eco-friendly flame retardant, inventory management, volume reduction, sunray thin client, Asus Eee pc and ultra portables.

Presented in [7] is a study that showed that there are certain green applications, which will replace the energy consuming applications negatively affecting the environment. Researches in relevant fields have been discussing ways on how to go green and avoid unnecessary power consumption. These discussions produced applications like Blackle and zonbu computer that were developed and introduced to the market as a solution toward green life.

A study in [8] aimed to show that companies/ institutions can help establish green life by adopting green computing concept. The information technology (IT) industry is putting great efforts to go green in all its sectors. There are key IT initiatives towards green computing including "cloud computing power management, making paper usage less, spreading the concept of recycling". The objective of this study was to find out current issues related to green computing.

The conclusion of the study in [9] showed that current trends for green computing concept refers to how to reduce pollution and save the planet from global warming by avoiding excessive energy consumption. The environmental protection agency pronounced that about $30-40 \%$ of computers kept ON even if they are unused and about $90 \%$ of them remain idle, thus, Climate Savers Computing Initiative is the solution to energy waste.

Various aspects of green technology are presented in [10]. They detail important features stemming from the adoption of the concept of green technology in all industries. For instance, there are so many fields for ewaste and energy management that can enhance the green approach. The methodologies that were used in the referred paper were limited to the published literature 
including those in journals and books. The paper described the lifecycle of electronic equipment. Throughout the past decades electronic equipment use and waste had become an emerging problem that lead to concerns about the environment and public health. The authors concluded by proposing solutions in the case study such as adoption of the notion "everyone must start making the efforts to reduce, reuse and recycle.

A study in [11]shows that E-Learning, known as the process of learning and training from anywhere at any time through a mobile phone or computers or any smart device, can reduce papers usage and carbon footprint. Elearning methodology is an example of green computing.

In terms of introducing the subject of Green Technology at the graduation level, the computers and smart devices are important elements to study and make projects. Each individual should be ethically bound, and should familiar with the proper way to recycle unwanted (out of service) devices. In addition, a system should be adopted to make them available on the internet as ematerial.

The study was designed with the aim to bring up the level of awareness about green computing in higher education institutes, and thus to make its concept a successful management tool. To reach this aim first we introduce the potential approaches to green computing adoption as the following: Power management, Energy efficiency, Working online, E-mail, virtualization; Cloud computing. One of the approaches towards green computing is the utilization of energy in a green way. Institutions should start using solar energy to avoid fossil fuel and their bad emissions.

The study in [12] proposed an advanced dynamic energy-aware cloudlet-based model (DECM). This model uses cloudlet technique to assign the cloud-based infrastructure usage and services for achieving green computing. This model can enable green computing because it reduces energy consumption. The line-up of cloudlet model with dynamic programming addresses a trusted party that can be either a computer or a cluster of digital devices with software that provides cloud users with a rapid response and specific functionalities. The positive results of this model were collected from an experiment designed to test the efficiency of the model. The reached conclusion showed that the approach was verified as a productive method for the cloudlet -based deployment in a dynamic circumstance.

Based on the knowledge that has been presented in previous studies, we found that the studies in [6] and [7] conclude that the world is facing serious issues because of the overuse of power and the wrong disposition of EWaste, which leads to damage to the environment and effects people's health. Hence, it is necessary to implement a good solution to avoid more impact on the environment and associated problems. Green computing and green design can solve these issues and produce good practice.

Based on the studies [8] and [9], green IT is every individual's responsibility for the protection of the environment., They added that computer and other electronic devices are increasing in numbers with time, and after a while they are destined for set out as garbage., If they are disposed in incorrect ways they will be left to produce $\mathrm{CO} 2$ as a by-product. Therefor, the solution for such E-Waste is recycling and adoption of ways to reduce energy consumption.

Referring to study [10], there are so many ways that were taken toward healthy environment. These include using green computing; cloud computing, energy consumption reduction and virtualization. In addition, proper E-Waste disposal plays a major role toward cleaner environment and green life. Spreading the importance of E-Waste reduction and its proper disposal will be reflected on the economic situation and the environment. Designing green equipment may reduce the need for cycling and reduce the amount of E-Waste.

As it is shown in [11] e-learning can be a good alternative to traditional learning because it reduces paper use, and thus production, which is known to be harmful to the environment. Therefor using emails, videos, faxes and pdf files in e-learning and in business sectors is the right means to implement for green computing. Companies in IT industries should take serious steps toward green designing and use of more cloud computing based software instead of the traditional local server-based ones.

\section{Methodology}

Interviews were selected as the approach to collected feedback from the company employees recruited for the current study. Discussions between the researcher and a person or a group of people that are related to the topic were recorded to collect information relevant to computing in relation to the environment and energy consumption. The personnel's interviewed were either managers or employees. The type of methodology that was adopted in this paper was the qualitative research interviews [11]. This type is useful for our research because it allowed us to gather more information in shorter time, and gave us the option to ask follow-up questions. This type can make the interviewee more fluent to express themselves and knowledge with regard to the main subject.

The company targeted in the study presented in this paper is AGOCO. It is headquartered in Benghazi-Libya, which was chosen because it is one of the largest national companies wholly owned by the Libyan state. It undertakes all stages of the oil and gas industry in Libya; the company's main activities include exploration, production of crude oil, natural gas, condensate, and refined oil products [13].

The interview was conducted with the employees and the head of the Computer Management Department on October, the 30th, 2019 on the company's main headquarters in Benghazi. 


\subsection{Interview Details}

Below is the interview details including all the discussed questions between the authors and the head of the company's Computer Management Department.

Q1: How many computers does this company have in the main headquarter?

Comment: About 950 devices.

Q2: How many computers are available in the company according to managements?

Comment: Administrative Affairs Department has 68 computers, Exploration Management has 60 computers and financial management has 82 computers.

Q3: What are the types and models of the computers at the company?

Comment: The type is Desk-top made by HewlettPackard Company (HP).

Q4: What are the operating systems for these computers? Comment: The operating systems are windows serves 2012, windows 7.

Q5: How many servers does this company have?

Comment: There are about 16servers.

Q6: How many data centers are inside the company?

Comment: There are two data centers.

Q7: What are the types of the screens used with computers, and what is their model if possible?

Comment: The Company has screens of the types HPLED, and HP LCD.

Q8: Is the company anchored in cloud computing?

Comment: The answer was negative.

Q9: Is it possible to estimate the percentage of cloud computing usage based on the volume of business?

Comment: It is $10 \%$.

Q10: How many printers does this company have?

Comment: nearly 400 .

Q11: What is the most used printer type in the company?

Comment: HP and EPSON.

Q12: Has the company had any experiment to move on toward eco- friendly field?

Comment: Yes, in safety field.

Q13: Does the company plan to implement green computing concept as one of the company's strategies?

Comment: Yes.

Q14: Is there any desire to spread the concept of green computing and sustainable development inside the company to raise the awareness between employees?

Comment: The answer was positive, but they are yet to take the necessary steps.

Q15: What is the capacity of the stand-by electrical generators inside the company?

Comment: The capacity is too big because there is so many of them.

Q16: What is the extent of fuel usage (High, Medium or Low).

Comment: Medium.

Q17: Is it possible to measure gas emissions from them? (Low, Medium, High, Very High)

Comment: The gas emission by the company is considered to be medium.

\subsection{Data Analysis}

Based on the answers provided by the study participants for the interview questions, the authors were capable to come up with the following anticipations: As shown in the comments in relation to questions 1 and 2,it is clear that the number of computers in use is large, which means there is high power consumption, thus increased energy emissions. The impact on the environment is further complicated by the large number of printers explained in the comment for question 10, which leads to higher energy consumption plus the increased ink consumption with its disadvantages and harmful smell.

In the comments for questions 2 and 3departments such as the of the Administrative Affairs and the Financial Affairs use traditional computers that could be oversized compared to the work assigned to it. Therefore, getting to use environment-friendly alternatives in such departments would be a lot rewarding. When it comes to the comment for question 8 , we could see that the company is far from using the simplest and most important methods in green computing, i.e. the cloud computing. As shown in the comment for question 9, the percentage of using cloud computing is $10 \%$, which is a very low percentage for a company such as AGOCO. In the comments for questions 12,13 and 14 we found that the company has the desire to transform into more environment-friendly methods in the field and head to green computing. In the comment for question 17 the company's gas emissions rate is medium, which is considered harmful to the environment.

Table 1 presents the average of high-power consumption of several devices used in AGOCO Company.

TABLE 1.Average power consumption in the company

\begin{tabular}{|l|l|}
\hline Component & $\begin{array}{l}\text { Average power } \\
\text { consumption (Watts) }\end{array}$ \\
\hline Servers & 200 watts per hour \\
\hline Devices & 180 watts per hour \\
\hline Printers & 47 watts per hour \\
\hline
\end{tabular}

\subsection{The proposed Devices}

As shown in Table 1 the range of power consumption is very high, hence there is need to clarify the newly proposed system, which is called Thin Client. It is totally new system used as an alternative to traditional desktops [14].

Thin Client is a new system that makes user, with only one keyboard, a mouse and a display screen, able to access and save data on a central server that can be anywhere in the world [15]. It helps users cancel the need for multiple task means, such as: anti viruses, fire wall and updating. Thin Client benefits are clear, the cost of infrastructure is low and its maintenance is much lower compared to the conventional multi-computer system [15]. 
Table 2 presents a comparison between Thin Client and the HP devices that the company uses. It shows the immense difference that reinforces the need for Thin Client system.

TABLE2.Comparison between Thin Client and HP

\begin{tabular}{|l|l|c|c|}
\hline Type & $\begin{array}{l}\text { power } \\
\text { consumption } \\
\text { Per One } \\
\text { Device }\end{array}$ & $\begin{array}{l}\text { power } \\
\text { consumption } \\
\text { of 100 } \\
\text { Devices }\end{array}$ & $\begin{array}{l}\text { power } \\
\text { consumption of } \\
\text { 950 Devices }\end{array}$ \\
\hline $\begin{array}{l}\text { Thin } \\
\text { client }\end{array}$ & $\begin{array}{c}\text { Watts per } \\
\text { hour }\end{array}$ & $\begin{array}{c}700 \text { Watts } \\
\text { per hour }\end{array}$ & $\begin{array}{c}\text { 6650 Watts per } \\
\text { hour }\end{array}$ \\
\hline HP & $\begin{array}{c}180 \text { Watts } \\
\text { per hour }\end{array}$ & $\begin{array}{c}18000 \text { Watts } \\
\text { per hour }\end{array}$ & $\begin{array}{c}171000 \text { Watts per } \\
\text { hour }\end{array}$ \\
\hline
\end{tabular}

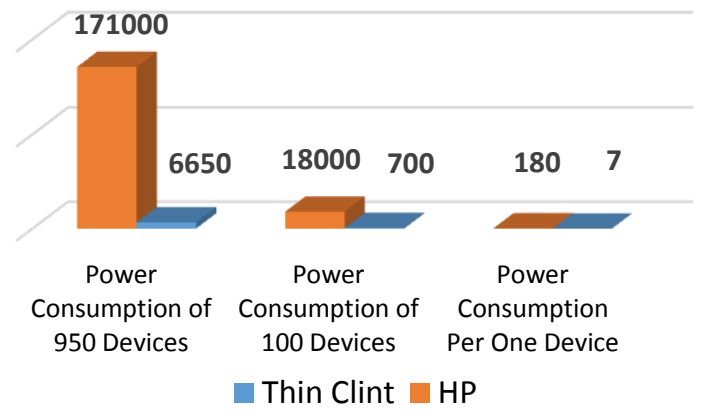

Fig1. Comparison between Thin Client and HP

As shown in Table 2 and Figure 1 the differences in power consumption and the proposed solution to move on toward green computing and the current situation.

The power consumption moving to Thin Client will be $25.7 \%$ times less than the currently used HP computers, which means that the power consumption will be reduced by $96.7 \%$. This percentage is significant and the power consumption is reduced to considerable levels.

\section{Recommendations}

\subsection{General Recommendations}

- Approval of technologies that use less energy for computers and other electronic devices, thus using the needed devices in an appropriate way that does not harm the environment.

- Disposing and recycling out of service electronic devices in a safe way.

- The concept of green computing must be published to the community by sending e-mails, messages, advertisements in the television and radio ....etc.
4.2 Specific Recommendations

- AGOCO must take the measurements of thermal emissions each 3 months.

- They must use cloud computing inside the company, which is considered to be the most important technique that helps green computing. In addition, it helps reduce the usage of devices and in return reduces the power consumption.

- The company must reduce using the energy from all departments by reducing the usage of devices with big waste of electronic energy.

- They should use fewer servers and replace the old ones with virtual servers.

- AGOCO needs to recycle unwanted devices to help protect the environment and reduce pollution.

- Using thin client or zero clients as a primary stage can be started from Administrative Affairs Department because it doesn't need so many computers.

- The company must encourage the employees to use green computing techniques and give them instructional courses about its concept.

\section{Conclusion}

The aim of this study is to focus on the main trace of power consumption, the importance of decreasing emissions, and to bring to attention the green computing concept. Such beneficial concept will contribute to creating healthy environment. One of the biggest oil companies in Libya, the AGOCO was selected for the case study presented in this paper.

The study was conducted through interviews with the Computer Department Manager and the company's employees. Important information and data were gathered such as, if there is any overuse of power based on the number of devices and printers in the company, and the extent of knowledge of the company about the green computing concept, and the administration desire to adopt it, in addition to other information that lead to analysis and other conclusions.

The new system called Thin Client is suggested as a solution to help reduce the power needed inside the company. The proposed system will help reduce the power consumption by $96.7 \%$ and this high percentage will lead to satisfactory results in terms of green computing. Finally, general and specific recommendations were suggested.

\section{References}

[1] D. Wang, Meeting green computing challenges, in 10th Electronics Packaging Technology Conference, 121-126, (2008). 
[2] S. Biswajit, IJCTT. 14, 46-50, (2014).

[3] T. Kumar, P Kiruthiga. Int. J. Eng. Res. 3, 356-359, (2014)

[4] S. Biswajit. IJCTT. 14, (2014)

[5] R. Hamron, N. Auseklis, in proceeding of Portland International Conference on Management of Engineering \& Technology, (PICMET), 1707-1717, (2009).

[6] K. Raza. V.K. Patle, S. Arya, JCIES. 1. 3-16 (2012).

[7] V. Deeve, N.V., V. Joe, C., N., k. Int. J. Curr. Res .7 14442-14445 (2015).

[8] A. Shibly. (2015). Green Computing: - Emerging Issue in IT. 10.13140/RG.2.1.1729.4248.

[9] K. Arora, G. Kohli, P. Ratta. Ijsrcseit. 4, 326-329 (2018)

[10] D. Biswajit, R. Reshma, S. Ghosh. Procedia. Environ. Sci. 35, 669-675 (2016)

[11] A. Shalabh, G Shreya, N. Asoke. Int. J. Comput. Appl 76, 7 (2013).

[12] G. Keke, Q. Meikang, Z. Hui, T. Lixin, Z Ziliang. J. Netw 59, 46-54 (2016)

[13] F. Shuaeib, M. Buraziza. Investigation and Evaluation of the Maintenance Management System of the Gas Turbines at the Arabian Gulf Oil Company (AGOCO). , in Proceedings of the Conference: 10th Mediterranean petroleum conference and exhibition, 26-28 Feb 2008, Tripoli, Libya

[14] J. Nieh, S. Yang, N. Novik. ACM Trans. Comput. Syst. 21, 87-115 (2003)

[15] Hirokazu Kanda "Thin client systems, server apparatus, client apparatus, and storage medium," US Patent 8,453,069,2013. 